\title{
Global distribution of the migrating terdiurnal tide seen in sporadic E occurrence frequencies obtained from GPS radio occultations
}

\author{
Tilo Fytterer $^{1 *}$, Christina Arras ${ }^{2}$, Peter Hoffmann ${ }^{3}$ and Christoph Jacobi ${ }^{4}$
}

\begin{abstract}
Global Positioning System radio occultation measurements by FORMOsa SATellite mission-3/Constellation Observing System for Meteorology, lonosphere and Climate satellites were used to analyse the characteristics of the 8-h oscillation in sporadic $E\left(E_{S}\right)$ layers. Six-year averages based on the 3-monthly mean zonal means from December 2006 to November 2012 were constructed for the amplitude of the terdiurnal oscillation in the occurrence frequency of $E_{s}$. A global distribution from $60^{\circ} \mathrm{S}$ to $60^{\circ} \mathrm{N}$ is given, revealing two peaks above $100 \mathrm{~km}$ during solstice with one maximum at low and midlatitudes (approximately $10^{\circ}$ to $40^{\circ}$ ) in each hemisphere. During equinox, the global distribution is marked by two dominant peaks centred at midlatitudes, while an additional weak maximum is located at very low southern latitudes. The seasonal characteristics around $110 \mathrm{~km}$ reveal large values during equinox at low and midlatitudes $\left(<40^{\circ} \mathrm{N}\right)$, while further peaks occur in April at $>40^{\circ} \mathrm{S}$ and in July near $30^{\circ} \mathrm{S}$. The pattern around $90 \mathrm{~km}$ is dominated by a broad peak between $20^{\circ}$ and $30^{\circ} \mathrm{S}$ from March to September. Comparisons with the terdiurnal oscillation in the neutral atmosphere derived from zonal wind and vertical zonal wind shear simulated with a circulation model of the middle atmosphere, as well as with satellite observations of the terdiurnal tide in temperature, fit quite well for the results above $100 \mathrm{~km}$, but do not show agreement for lower altitudes.
\end{abstract}

Keywords: Sporadic E layer; Terdiurnal tide; Wind shear theory; GPS radio occultation

\section{Background}

The wind field of the mesosphere/lower thermosphere (MLT) is strongly influenced by atmospheric solar tides. One of them, which had attained some attention during recent years, is the migrating terdiurnal tide with a period of $8 \mathrm{~h}$ and a zonal wave number 3 (referred to as TDT here). The TDT is thought to be excited both directly by the terdiurnal component of solar radiative heating and indirectly by wave-wave interactions between the semidiurnal tide (SDT) and the diurnal tide (DT) (Teitelbaum et al. 1989). Model studies indicate that nonlinear interactions contribute to the TDT preferably at low and midlatitudes (Smith and Ortland 2001; Huang et al. 2007). The TDT amplitudes in wind are generally smaller than the ones of the SDT and DT;

\footnotetext{
* Correspondence: tilo.fytterer@kit.edu

'Institute for Meteorology and Climate Research, Karlsruhe Institute of Technology, Hermann-von-Helmholtz-Platz 1, Eggenstein-Leopoldshafen 76344, Germany

Full list of author information is available at the end of the article
}

therefore, earlier investigations had focused on the latter ones, and the seasonal and global distribution of the TDT is not that well known. However, taking into account that during some seasons and depending on altitude and latitude, the TDT has amplitudes of similar magnitude to DT or SDT, it may be assumed that the TDT also plays an important role in dynamics of the MLT.

Observations of the TDT are still relatively rare, at least compared to those of the SDT and DT. The first global characteristics of the TDT in wind at $95 \mathrm{~km}$, derived from Upper Atmosphere Research Satellite/High Resolution Doppler Imager observations, have been reported by Smith (2000), revealing larger amplitudes during winter and autumn at midlatitudes while the zonal wind component is larger than the meridional one. More recently, satellite temperature measurements have been presented by Moudden and Forbes (2013), using Thermosphere, Ionosphere, Mesosphere Energetics and Dynamics/Sounding of the Atmosphere using Broadband Emission Radiometry (TIMED/ SABER) data from 2002 to 2011. These investigations show 
that the migrating TDT is the strongest component among all 8-h oscillations. Also apparent is a transition layer near $100 \mathrm{~km}$, where the TDT amplitude becomes more pronounced at middle and high-latitudes, while below $100 \mathrm{~km}$, the amplitudes dominate in the tropics. Using a similar data set and considering the years 2002 to 2009, Pancheva et al. (2013) presented seasonal patterns of the TDT. The results at $90 \mathrm{~km}$ display the strongest amplitudes during boreal late winter/spring and a secondary maximum in autumn near the equator and northern midlatitudes. However, at around $110 \mathrm{~km}$, the largest values are found during equinox at northern midlatitudes while a three peaking structure at southern midlatitudes is also evident, maximising during equinox and around June. Further TDT satellite measurements in temperature and zonal wind derived from both SABER and TIMED Doppler Interferometer (TIDI) data as well as a general circulation model (GCM) are reported by Yue et al. (2013), additionally revealing three peaks at midlatitudes and at the equator region at altitudes above 95 $\mathrm{km}$. The characteristics of the midlatitude TDT observed by radar have been described on few occasions (e.g. Beldon et al. 2006; Jacobi and Fytterer 2012). Often, the zonal wind amplitude has been found to be larger than the meridional one. A clear seasonal cycle is apparent, at midlatitudes with smaller amplitudes in summer and two maxima in spring and autumn, while the latter one is dominating. The amplitudes range from 1 to $10 \mathrm{~m} / \mathrm{s}$ at altitudes of $90 \mathrm{~km}$, depending on season and latitude.

Sporadic E $\left(E_{S}\right)$ layers are thin clouds of accumulated plasma, primarily occurring at midlatitudes during summer (Garcia-Fernandez and Tsuda 2006). They are generally formed at altitudes between 90 and $120 \mathrm{~km}$, which is equivalent to the upper MLT and the lower ionospheric E region. According to wind shear theory (Whitehead 1961), the forming process of $E_{S}$ is an interaction between the Earth's magnetic field, the ion concentration, as well as the vertical wind shear. Neglecting diffusion, the vertical component of the neutral gas velocity, and the electric force, the vertical ion drift $w_{\text {Ion }}$ can be written as:

$$
w_{\text {Ion }}=\frac{r \cdot \cos I}{1+r^{2}} U-\frac{\cos I \cdot \sin I}{1+r^{2}} V
$$

where $U$ and $V$ are the zonal and meridional wind components of the neutral gas, while $I$ represents the inclination of the Earth's magnetic field lines. The parameter $r=v_{\text {Ion } / N} / \omega$ describes the ratio of the ion-neutral gas collision frequency $v_{\text {Ion } / N}$ and the gyro frequency $\omega=e \cdot B_{0} / m_{\text {Ion }}$. Here, $m_{\text {Ion }}$ is the ion mass, $e$ is the elementary charge, and $B_{0}$ is the total intensity of the Earth's magnetic field. Note that in Equation 1, in contrast to the usual notations in literature, Cartesian coordinates $x, y$, and $z$ are used, pointing eastward, northward, and upward, respectively. Considering that $r>>1$ below approximately $115 \mathrm{~km}$ (Bishop and Earle 2003), the zonal wind component is much more efficient in causing vertical plasma motion than the meridional wind component. Consequently, the second term of Equation 1 may be neglected in the lower E region, implying that negative vertical zonal wind shear primarily leads to the formation of $E_{S}$. Note that Equation 1 holds only for magnetic midlatitudes (approximately $20^{\circ}$ to $70^{\circ}$ ) where electric forces can be neglected.

Assuming that solar tides are the main source of the vertical wind shear, frequently providing larger vertical gradients than the background wind, tidal-like structures are expected in $E_{S}$ occurrence. Actually, the SDT and $\mathrm{DT}$ are generally accepted to be the major driver of $\mathrm{E}_{\mathrm{S}}$ (Mathews 1998), leading to the reproduction of downward moving tidal signatures, e.g. in $\mathrm{E}_{\mathrm{S}}$ ionosonde registrations (e.g. Haldoupis et al. 2006). These tidal signatures in neutral wind and $\mathrm{E}_{\mathrm{S}}$ occurrence can be also modulated by the planetary quasi 6-day wave (Zuo and Wan 2008). By combining Global Positioning System (GPS) registrations and radar wind measurements, Arras et al. (2009) have shown that $E_{S}$ occurrence frequencies actually maximise when the zonal wind shear provided by the SDT is negative. More recently, Fytterer et al. (2013) found a clear correlation between midlatitude radar zonal wind shear and $\mathrm{E}_{\mathrm{S}}$ for the 8-h component, leading to the conclusion that not only DT and SDT but also TDT contributes to $\mathrm{E}_{\mathrm{S}}$ formation. However, the latter results were restricted to northern midlatitudes, but have encouraged us to extend the investigations to a global scale.

Therefore, in this paper, we analyse the terdiurnal oscillation in $E_{S}$, obtained from GPS radio occultation (RO) measurements by the FORMOsa SATellite mission-3/ Constellation Observing System for Meteorology, Ionosphere and Climate (FORMOSAT-3/COSMIC). The results will be compared with the dynamical model output of a circulation model of the middle atmosphere and discussed in the light of global analyses obtained from TIMED/SABER and TIDI measurements as well as modelling results in the literature (Pancheva et al. 2013; Moudden and Forbes 2013; Yue et al. 2013; Du and Ward 2010).

\section{Methods}

\section{Radio occultation measurements}

The GPS RO technique bases on the radio link between GPS satellites and low-Earth-orbiting (LEO) satellites. Due to the low Earth orbits and the relatively short orbital period of the LEOs, the GPS satellites are nearly fixed with respect to them and are observed as setting or rising objects. During these occultations, the ionosphere is vertically scanned, because the propagating radio waves are modified according to the atmospheric refraction index, 
which depends on the electron density. Fluctuations of the electron density disturb the GPS signal and cause divergence/convergence effects, which lead to decreased/increased intensity of the detected radio wave. The $E_{S}$ signature can be extracted from the background noise by analysing the signal-to-noise ratio (SNR; Wu et al. 2005; Arras et al. 2008).

The procedure of analysing $E_{S}$ from GPS RO has already been described in Arras et al. $(2008,2009)$ and Fytterer et al. (2013) and is therefore only briefly outlined here. We use the standard deviation of the normalised SNR during an occultation, and if it exceeds a threshold of 0.2 and increases by more than 0.14 between two adjacent intervals, the signature is accepted as an $E_{S}$. The height of the largest deviation from the mean profile is regarded as the approximate altitude of the $E_{S}$. The $E_{S}$ is located where the radio wave is most refracted (tangent point).

The main advantages of the GPS RO method are the global coverage and the high vertical resolution. In contrast, no continuous time series on short scales and no quantitative measurements of individual $\mathrm{E}_{\mathrm{S}}$ are available, but monthly and inter-annual variability can be investigated by simply counting the number of $\mathrm{E}_{\mathrm{S}}$ occurrences. Therefore, the figures in this study concerning $\mathrm{ROs} / \mathrm{E}_{\mathrm{S}}$ show 3-monthly sum/mean zonal sums/means for December to February (DJF), March to May (MAM), June to August (JJA) and September to November (SON). The investigated mean latitudes range from $60^{\circ} \mathrm{S}$ to $60^{\circ}$ $\mathrm{N}$, shifted by $5^{\circ}$, and each interval covering an area of $10^{\circ}$ around the given mean latitude. Averages over a sliding height window of $11 \mathrm{~km}$, shifted by $1 \mathrm{~km}$, were calculated, and the reference height was taken as the centre of the interval.

The six FORMOSAT-3/COSMIC satellites are operating since summer 2006, and the data set from November 2006 to December 2012 (3-monthly means from December 2006 to November 2012, respectively) was used for constructing the TDT climatology. Figure 1 displays 6-year sums of the global pattern of $\mathrm{RO}$ measurements during DJF, showing a symmetrical structure with respect to the equator, where also a minimum number is located. The maxima occur around $25^{\circ}$ and $50^{\circ}$, while the latter one is slightly larger. At high latitudes $\left(>60^{\circ}\right)$, RO measurements are strongly decreasing due to the inclination of the GPS satellites. The occurrence numbers are nearly uniformly distributed throughout the year (not shown here). However, considerably lower RO count rates (reduced by a factor of 2) were detected from November 2010 to February 2011 because satellites were out of contact or new firmware was tested (CDAAC Team 2014), while in January, February, May and June 2012, the RO profiles did not extend to the ionospheric E region in many cases. However, a sufficient

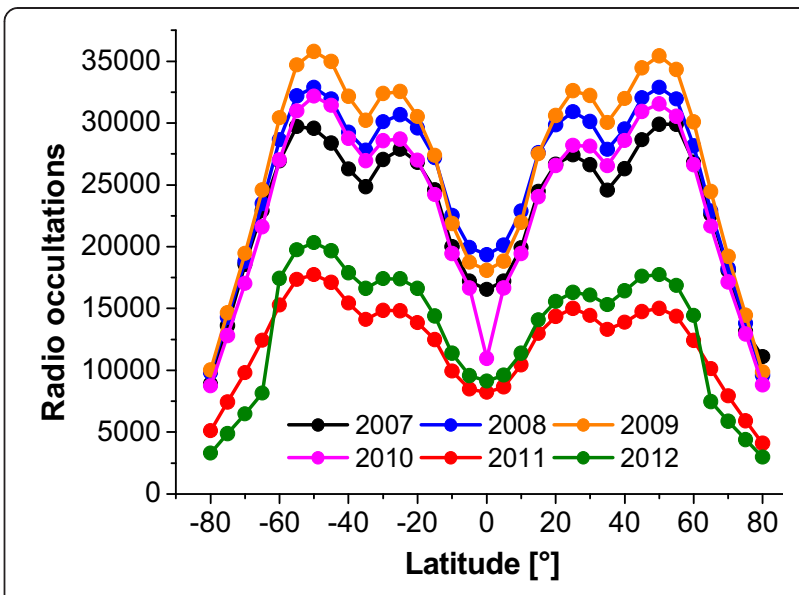

Figure 1 Number of radio occultations as a function of latitude from 2007 to 2012. Shown are 3-monthly (December to February) count rates measured by the FORMOSAT-3/COSMIC satellites over all longitudes, covering $10^{\circ}$ around the given mean latitude, shifted by $5^{\circ}$.

amount of data was still available for regions $\leq 60^{\circ}$ mean latitude.

Figure 2 shows the total number of $\mathrm{E}_{\mathrm{S}}$ (upper row) and the respective occurrence frequency (OF, lower row). The $\mathrm{OF}$ is the number of detected $\mathrm{E}_{\mathrm{S}}$ divided by the respective number of RO and provided here in 1/1,000 for more handy values. During DJF (left column), the summer hemisphere reveals a broad maximum at midlatitudes $\left(20^{\circ}\right.$ to $50^{\circ}$ ), reaching values $>4,000 \mathrm{E}_{\mathrm{S}}$, while in winter approximately half that many events were detected and the maximum is shifted towards lower latitudes $\left(20^{\circ}\right.$ to $\left.25^{\circ}\right)$. During MAM (right column), the global structure is quite symmetric about the equator, and moderate $E_{S}$ numbers between $20^{\circ}$ to $30^{\circ}$ are visible. On average, the Northern Hemisphere reveals slightly greater OF due to the low horizontal component of the Earth's magnetic field in the region of the South Atlantic Anomaly (e.g. Arras et al. 2008), which leads to smaller zonal mean $E_{S}$ occurrence numbers. Essentially lower $\mathrm{E}_{\mathrm{S}} \mathrm{OFs}$ are mainly found above $115 \mathrm{~km}$ and below $90 \mathrm{~km}$. Therefore, in later discussions, the shown maximum height is reduced to $115 \mathrm{~km}$, but the lower altitudes are still required for comparisons with model data.

\section{Numerical modelling}

The Middle and Upper Atmosphere Model (MUAM; Pogoreltsev et al. 2007) is a 3D nonlinear mechanistic gridpoint model of the neutral atmospheric circulation, basing on the Cologne Model of the Middle Atmosphere-Leipzig Institute for Meteorology (COMMA-LIM; Fröhlich et al. 2003). MUAM has a latitude/longitude resolution of $5^{\circ} \times$ $5.625^{\circ}$, while the entire height interval, extending from the $1,000 \mathrm{hPa}$ surface up to the altitudes of the ionospheric F2layer, is divided in 60 evenly spaced levels. The vertical 

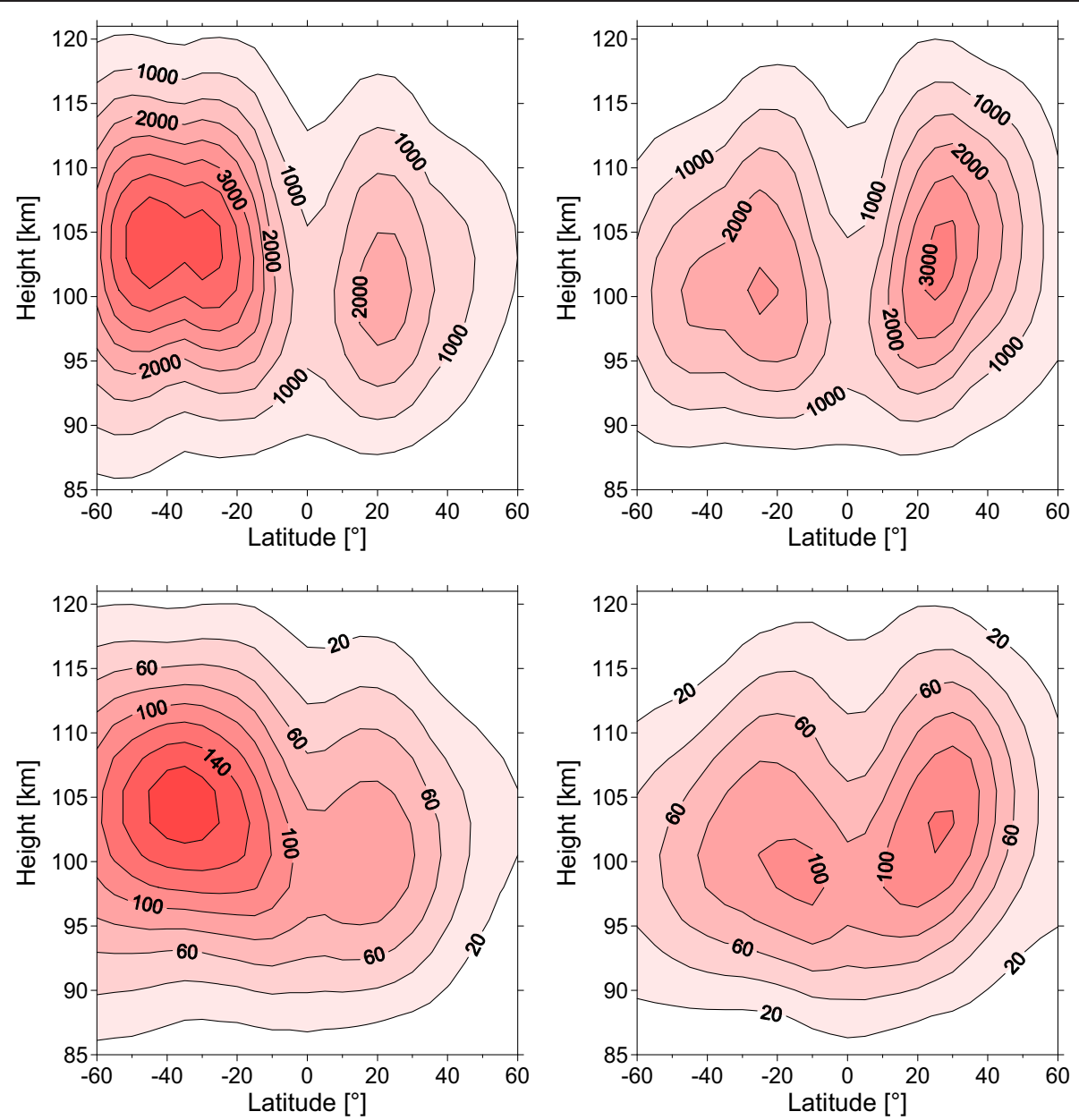

Figure 2 Latitude-height cross sections of the total number/occurrence frequency $(1 / 1,000)$ of sporadic $E$ layers (upper/lower row). Shown are 3-monthly mean zonal means over an 11-km sliding height interval for solstice (December to February, left column) and equinox (March to May, right column), using the FORMOSAT-3/COSMIC satellite data from December 2006 to November 2012.

coordinate is given by the nondimensional log-pressure height $\left[x=-\ln \left(p / p_{0}\right), p_{0}=1,000 \mathrm{hPa}\right]$ with a constant step size of about 0.4. This model allows using an arbitrary number of levels (ranging from 48 to 60 ) with the same vertical resolution. In the 60-level version, the upper boundary is placed at $x=24$ which corresponds to a geopotential height of 300 to $400 \mathrm{~km}$, depending on the thermospheric temperature.

The model solves the primitive equations. It includes gravity wave $(\mathrm{GW})$ parameterisation, parameterised ion drag, molecular heat conduction, Joule heating in the upper atmosphere and a full radiation scheme to allow self-consistent tidal forcing. The extreme ultraviolet (EUV) heating in the thermosphere is included. Solar fluxes and absorption coefficients for each EUV spectral interval and each constituent were calculated using the model proposed by Richards et al. (1994). The constant value of 0.366 for the EUV heating efficiency has been used as recommended by Roble (1995). To integrate the prognostic equations, the Marchuk-Strang approach was used, which includes splitting of the initial Cauchy problem into the set of simpler problems according to the considered physical processes (Marchuk 1967; Strang 1968). Finally, to solve the equations obtained in the result of splitting the Cauchy problems, we use the Matsuno (1966) time-integration scheme with a time step-size $100 \mathrm{~s}$.

In this study, the 48-level version of MUAM was used to investigate the basic climatology of the TDT amplitude in zonal wind and vertical zonal wind shear at altitudes up to $135 \mathrm{~km}$. Note that MUAM does not include any electrodynamics and therefore cannot reproduce the formation of $E_{S}$, so that we only compare the modelled wind shear variability with $\mathrm{E}_{\mathrm{S}}$. The lower boundary conditions are taken from the National Centres for Environmental Prediction and National Centre for Atmospheric Research reanalysis data, including monthly mean zonal mean temperature fields from 1,000 to $30 \mathrm{hPa}$ as well as 
geopotential height and the corresponding amplitudes and phases of the first three stationary zonal harmonics at $1,000 \mathrm{hPa}$. Monthly mean $\mathrm{O}_{3}$ concentrations were added. Each simulation started after a warm-up of 120 days, using a time resolution of $1 \mathrm{~h}$. The resulting model data were space-time spectrally analysed to calculate the individual tidal amplitudes. To derive the vertical zonal wind shear, the model output was linearly interpolated to $1-\mathrm{km}$ steps between 85 and $130 \mathrm{~km}$, again performing a space-time spectral analysis afterwards. The individual model runs refer to moderate solar activity, and the GW input parameters at the lower boundary were linearly changed between summer and winter conditions. Adding externally forced planetary waves (16-, 10- and 5-day wave) revealed only minor differences (not shown here). Note that the quasi 2-day wave was not considered here, which is justified because its impact on the $E_{S}$ formation is suggested to be relatively weak (Haldoupis et al. 2007).

\section{Results and discussion}

Observations of terdiurnal signatures in sporadic $E$ layers Amplitudes and phases of the 8-h oscillation in the OF of $E_{S}$ (referred to as 8-h $E_{S}$ here) were calculated by using a multiple regression analysis which included the mean OF as well as 24-, 12- and 8-h oscillations. Note that previously performed frequency-wave number analyses have ensured that the westward migrating component is the dominant 8-h oscillation of 8-h $E_{S}$ (not shown here), agreeing with the results presented by Moudden and Forbes (2013). The OF was sorted according to the local time (Figure 3, left panel), considering 3monthly mean zonal means of an 11-km height interval. The harmonic fit was applied for every month and mean altitude from 85.5 to $115.5 \mathrm{~km}$, while the time resolution was set to $1 \mathrm{~h}$.
As already described by Fytterer et al. (2013), the impact of DT and SDT has to be removed to validate the existence of the TDT. Therefore, for visualisation, the harmonic fit was also applied without the 8-h oscillation and consequently subtracted from the original OF. As an example, the obtained residuals for September to November 2010 are shown in Figure 3, right panel, revealing a clear 8 -h wave signature $>100 \mathrm{~km}$. Note that this generally holds for every month and latitude, assuring that the terdiurnal signatures seen in $\mathrm{E}_{\mathrm{S}}$ are a real physical feature at these altitudes. However, below $100 \mathrm{~km}$, the 8-h wave signal is quite disturbed, especially if $E_{S}$ OFs are low, occasionally showing a well-pronounced 6-h signal or even no clear wave-like structures. Here, the only clear 8 -h oscillation is found around $20^{\circ} \mathrm{S}$ from March to October, suggesting that features seen below $100 \mathrm{~km}$ might not be caused by the TDT in most cases. Also visible are the more pronounced 8-h residual amplitudes at noon and around 20 LT, associated with the general larger OF (Figure 3, left panel). Thus, the influence of the background cannot be neglected and was removed by dividing the 8-h $\mathrm{E}_{\mathrm{S}}$ by the respective 3-monthly mean zonal mean $\mathrm{E}_{\mathrm{S}} \mathrm{OF}$.

Figure 4 displays height-latitude cross sections of the normalised 8-h $\mathrm{E}_{\mathrm{S}}$ amplitude for solstice (DJF and JJA, left column) and equinox (MAM and SON, right column). To exclude irregular results, regions with the 6-y mean OF $>30 / 1,000$ are shaded, and only these areas are investigated in more detail. As indicated by the results of the harmonic analysis (see Figure 3, right panel), the 8-h $\mathrm{E}_{\mathrm{S}}$ amplitude reveals a change near $100 \mathrm{~km}$. In the region above, two strong maxima of the normalised 8-h $\mathrm{E}_{\mathrm{S}}$ amplitude are visible during solstice, occurring at low and midlatitudes (approximately $10^{\circ}$ to $40^{\circ}$ ) in both hemispheres. The magnitude of all maxima does not only depend on
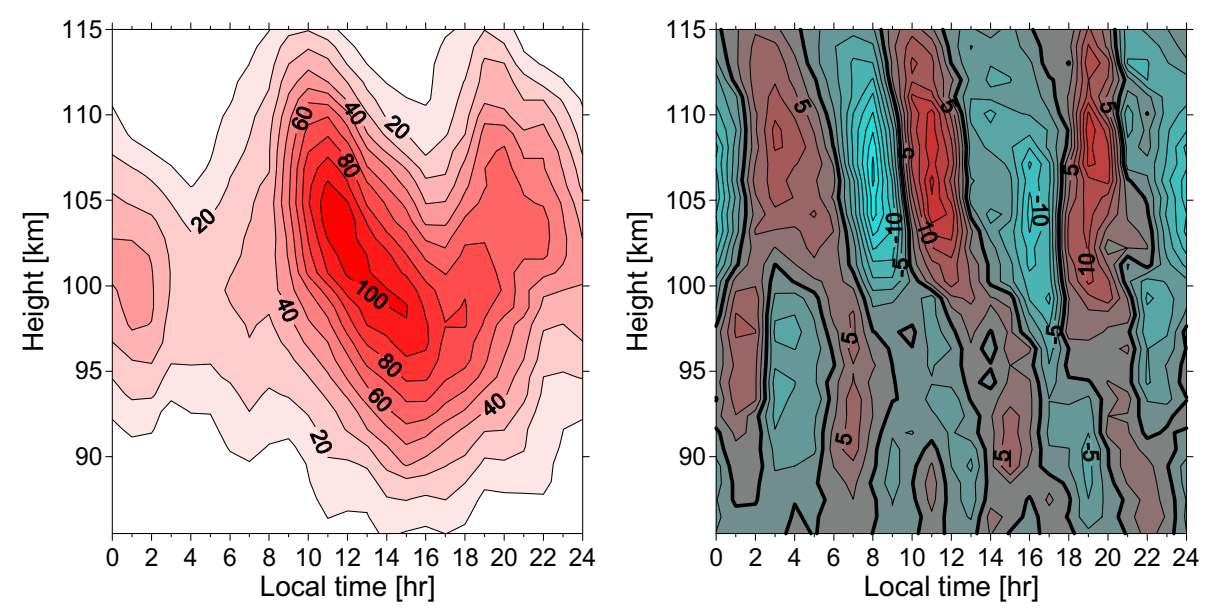

Figure 3 Example of occurrence frequencies $(1 / 1,000)$ of sporadic E layers (left) and the corresponding residuals (right). The residuals are the occurrence frequencies after the mean, 12- and 24-h oscillations were subtracted. Shown are 3-monthly mean zonal means of October (September to November) 2010, covering the latitudes from $43^{\circ}$ to $63^{\circ} \mathrm{N}$ 

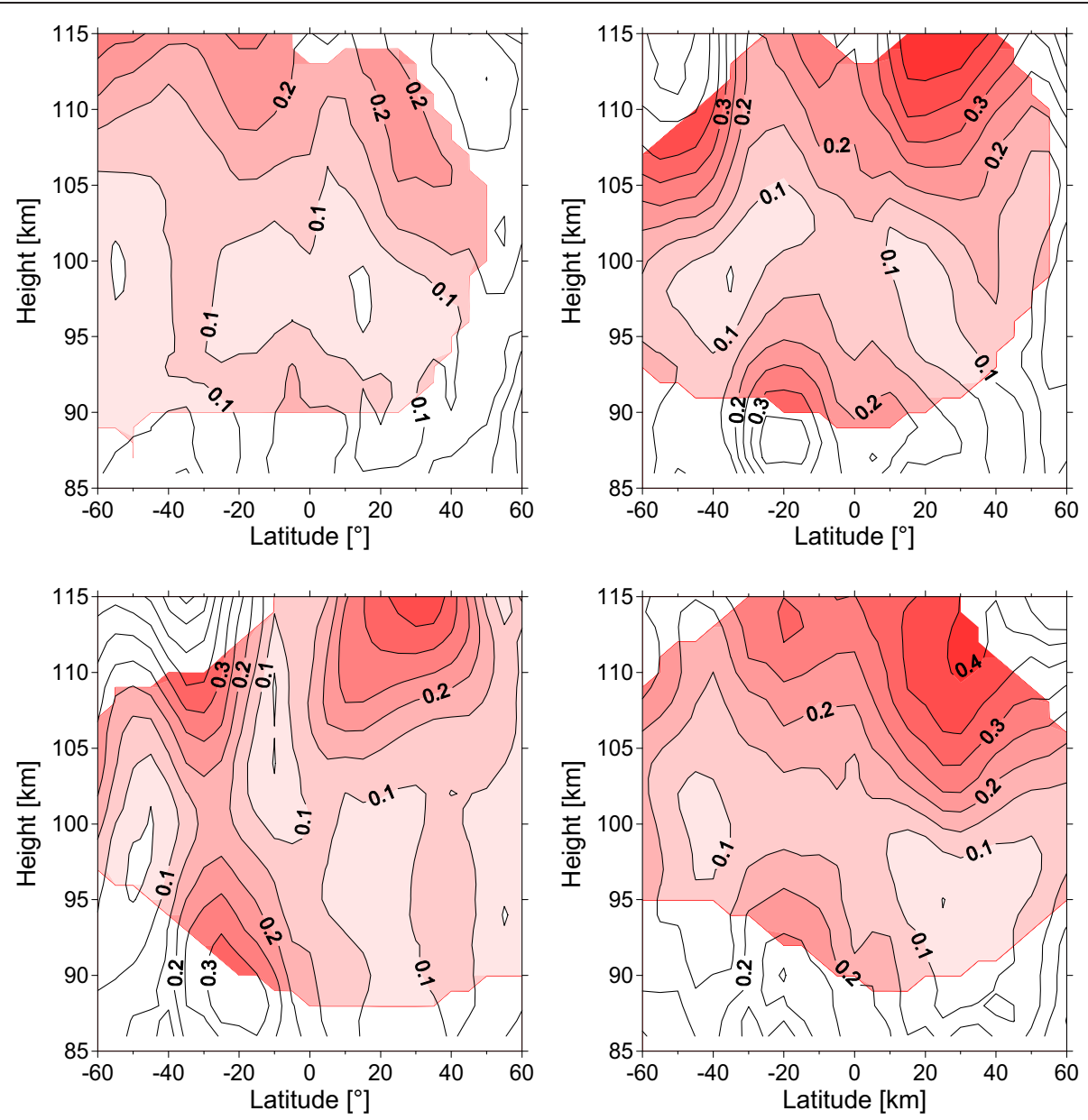

Figure 4 Six-year averages of the normalised amplitude of the 8-h $\mathrm{E}_{\mathbf{s}}$ for each season. The results show 3-monthly mean zonal means for winter (December to February, top left), spring (March to May, top right), summer (June to August, bottom left) and autumn (September to November, bottom right), derived from the FORMOSAT-3/COSMIC satellites measurements from December 2006 to November 2012. Reddish areas show regions with an occurrence frequency of sporadic E layers $>30 / 1,000$.

latitude but also on season, showing larger values during JJA (0.3 to 0.4) compared to DJF (0.2). During equinox, the meridional structure is marked by two peaks occurring between $10^{\circ}$ and $50^{\circ} \mathrm{N}$ and at $>30^{\circ} \mathrm{S}$, respectively. An additional but much weaker maximum is located at very low southern latitudes, probably owing to auroral $\mathrm{E}_{\mathrm{S}}$ of different origin. At lower altitudes ( 85 to $100 \mathrm{~km}$ ), the 8-h $\mathrm{E}_{\mathrm{S}}$ amplitude is generally smaller, except for one peak most likely maximising around $25^{\circ} \mathrm{S}$ below $90 \mathrm{~km}$, which occurs in MAM, JJA and SON. In contrast to the upper region, larger amplitudes are generally found at lower latitudes, surrounded by well-pronounced minima at midlatitudes, in particular during equinox. Another apparent pattern is the amplitude decrease between $90 \mathrm{~km}$ and $100 \mathrm{~km}$, possibly originating from a phase shift of $2 \mathrm{~h}$ (right panel of Figure 3; see also Jacobi and Fytterer 2012), leading to destructive superposition of at least two different wave modes.

To investigate the seasonal behaviour of the TDT in more detail, two latitude-time cross sections around 90 $\mathrm{km}$ and $110 \mathrm{~km}$ are shown in Figure 5 . At $90 \mathrm{~km}$, a broad maximum (0.3 to 0.4) from March to September centred at $25^{\circ} \mathrm{S}$ is evident as well as a secondary one (0.2) at $10^{\circ} \mathrm{N}$ in March. Smaller amplitudes are found from June to November at low northern latitudes. The 8-h $\mathrm{E}_{\mathrm{S}}$ amplitude near $110 \mathrm{~km}$ reveals a different pattern. The Northern Hemisphere at low and midlatitudes (approximately $10^{\circ}$ to $40^{\circ}$ ) is dominated by a semi-annual oscillation, maximising during equinox with slightly larger values in autumn $(>0.3)$. The maxima in the Southern Hemisphere are of similar magnitude, occurring poleward of $40^{\circ} \mathrm{S}$ around April as well as at $30^{\circ} \mathrm{S}$ in July. Furthermore, two smaller peaks are located near the equator in February and November.

\section{Modelling results}

The obtained meridional distribution of the normalised 8-h $\mathrm{E}_{\mathrm{S}}$ amplitude is compared with the TDT amplitude in zonal wind and the 8 -h oscillation in vertical zonal 

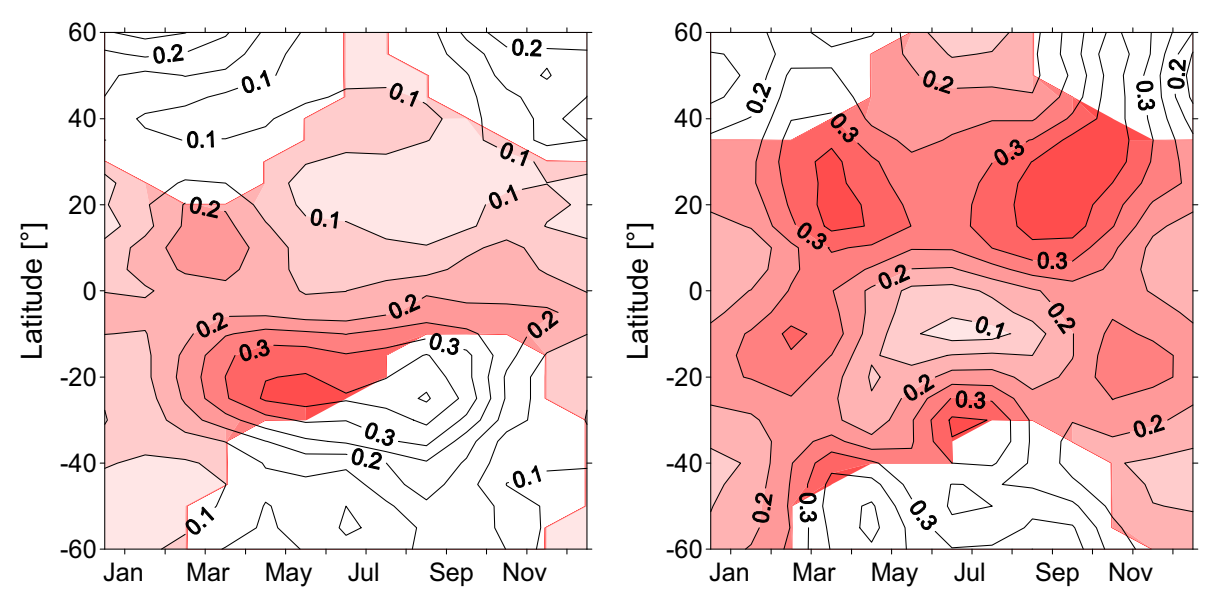

Figure 5 Latitude-time plot of the normalised amplitude of the 8-h oscillation at approximately $90 / 110 \mathrm{~km}$ (left/right panel). Shown are 6-year averages, based on 3-monthly mean zonal means derived from FORMOSAT-3/COSMIC satellite measurements from December 2006 to November 2012. Reddish areas show regions with an occurrence frequency of sporadic E layers $>30 / 1,000$.

wind shear (referred to as 8-h shear), simulated by MUAM (Figure 6). Here, January and April are shown, representing solstice and equinox conditions, respectively. Assimilated lower boundary data are taken for the year 2010. Note that the altitudes are given in logpressure heights, which are similar to the real altitudes from 80 to $95 \mathrm{~km}$ but increase the real altitudes by up to
$5 \mathrm{~km}$ between $95 \mathrm{~km}$ and $120 \mathrm{~km}$. In January, TDT and 8-h shear amplitudes show similar characteristics, and they are in good agreement with the observations of the 8-h $\mathrm{E}_{\mathrm{S}}$ amplitude displayed in Figure 4. Here, two maxima are evident, one nearly covering the Northern Hemisphere up to $50^{\circ} \mathrm{N}(10 \mathrm{~m} / \mathrm{s}, 1.6 \mathrm{~m} / \mathrm{s} / \mathrm{km})$ as well as a second one between the equator and $20^{\circ} \mathrm{S}(8 \mathrm{~m} / \mathrm{s}, 1.0$
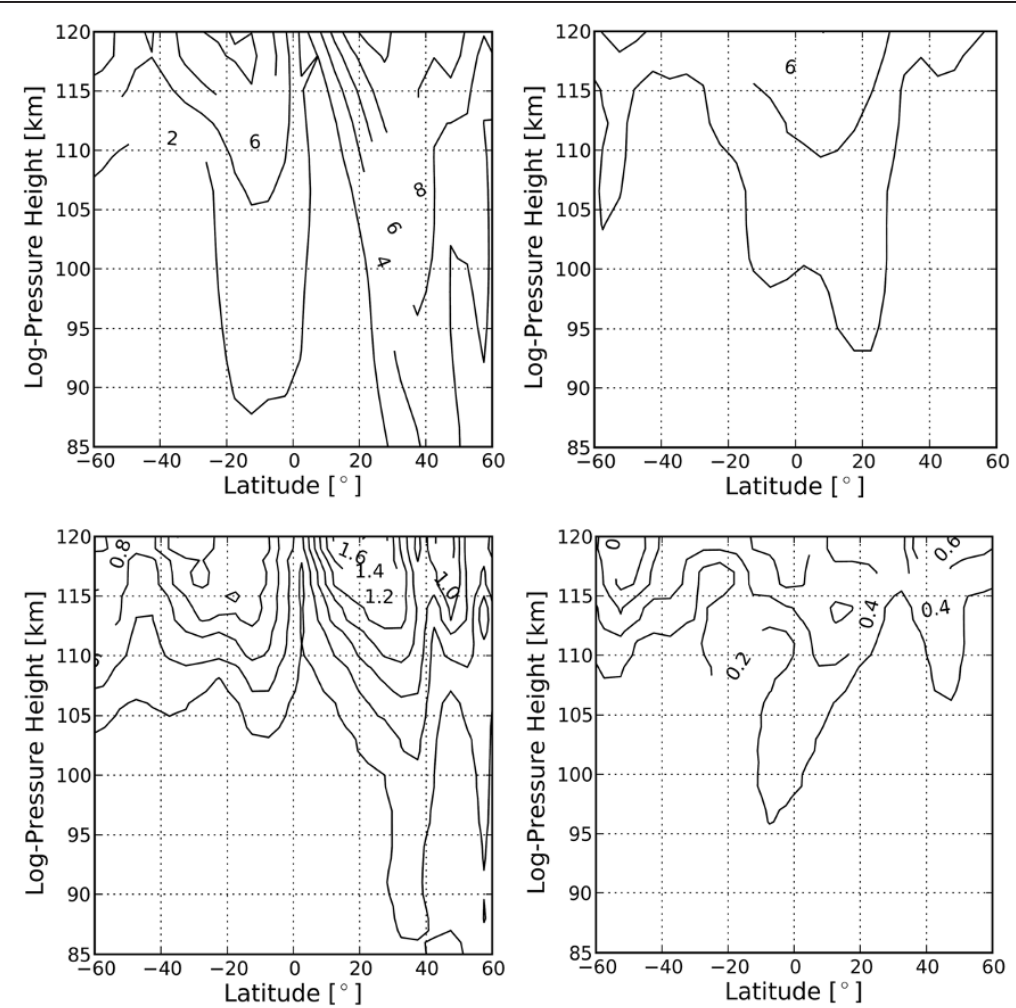

Figure 6 Terdiurnal amplitude in zonal wind (upper row) and in vertical zonal wind shear (lower row). Shown are the results for January (left column) and April (right column), simulated by MUAM. The contour intervals are $2 \mathrm{~m} / \mathrm{s}$ and $0.2 \mathrm{~m} / \mathrm{s} / \mathrm{km}$, respectively. 
$\mathrm{m} / \mathrm{s} / \mathrm{km})$. In April, the three-peak structure with maximum values between approximately $10^{\circ} \mathrm{N}$ and $20^{\circ} \mathrm{N}$ as well as at midlatitudes around $50^{\circ}$ in both hemispheres is visible, similar to the observed pattern in the OF and the GCM results reported by Yue et al. (2013). However, the Northern Hemisphere midlatitude peak is less pronounced in the TDT in zonal wind.

To summarise, the general output of MUAM above $105 \mathrm{~km}$ is in good agreement with the behaviour of 8-h $\mathrm{E}_{\mathrm{S}}$ amplitude. The two pronounced maxima in January as well as the three-peak structure during April are evident and only slightly shifted compared to the 8-h $E_{S}$ amplitudes. Note that the maximum near the equator during equinox is only weakly visible in the 8-h $\mathrm{E}_{\mathrm{S}}$, which is due to the generally small $E_{S} O F$ in those regions where the magnetic field lines are nearly horizontally oriented. However, as described in 'Observations of terdiurnal signatures in sporadic E layers' section, these $E_{S}$ might not originate from wind shear mechanism. Below $100 \mathrm{~km}$, the differences between model results and observed TDT in $\mathrm{E}_{\mathrm{S}}$ OF become larger, but the features are generally difficult to compare due to small TDT amplitudes and low $E_{S}$ OFs. In January, the TDT is only able to influence the $E_{S}$ formation at Northern Hemisphere midlatitudes around $50^{\circ} \mathrm{N}$, which cannot be seen in the data due to low $\mathrm{E}_{\mathrm{S}}$ OFs. Similar characteristics are not apparent, also holding for April where TDT and 8-h shear amplitudes are even smaller. Therefore, the dominant 8-h $\mathrm{E}_{\mathrm{S}}$ maximum near $20^{\circ} \mathrm{S}$ cannot be explained by the model results.

\section{Comparisons with results from the literature}

The latitude-height structure of the 8-h $\mathrm{E}_{\mathrm{S}}$ amplitude above $100 \mathrm{~km}$ fits quite well with the TDT behaviour observed in SABER temperatures from 2002 to 2009 (Pancheva et al. 2013, their Figures seven and eight). A three-peak structure is evident throughout the year in SABER temperatures, which is also seen in $E_{S}$ during equinox and can be at least guessed for solstice conditions. In contrast, at altitudes below $100 \mathrm{~km}$, the results do not match well, especially the dominating $\mathrm{E}_{\mathrm{S}} \mathrm{OF}$ maximum at low southern latitudes below $90 \mathrm{~km}$ during MAM and JJA is not found in TDT behaviour. However, the careful inspection of this feature has assured that the 8-h signal is not a mathematical artefact (see 'Observations of terdiurnal signatures in sporadic E layers' section). Additionally, the structure is present in every year and does not originate from a single large event. Considering the results reported by Moudden and Forbes (2013), who found larger TDT amplitudes in SABER temperatures from 2002 to 2011 near the equator, a link between TDT and 8-h $\mathrm{E}_{\mathrm{S}}$ at very low southern latitudes might be possible, because the magnetic field lines reveal dip angles up to $60^{\circ}$. However, this assumption cannot be validated, because wind shear mechanism is not efficiently working directly at the equator and at very low northern latitudes, where a similar pattern would be expected.

The seasonal cycle of the $8-\mathrm{h} \mathrm{E}_{\mathrm{S}}$ amplitudes at $90 \mathrm{~km}$ (Figure 5, left panel) is quite different from the TDT behaviour in temperature (Pancheva et al. 2013, their Figure four; Yue et al. 2013), primary due to the 8-h $\mathrm{E}_{\mathrm{S}}$ maximum near $25^{\circ} \mathrm{S}$. However, a good agreement was not expected at that height due to the low $\mathrm{E}_{\mathrm{S}}$ OFs and weak TDT activity in principle. Further results of the migrating TDT in zonal wind at $95 \mathrm{~km}$ by using the Canadian Middle Atmospheric Model (CMAM) were reported by $\mathrm{Du}$ and Ward (2010), revealing a similar extended maximum from April to October, but shifted to midlatitudes (approximately $50^{\circ} \mathrm{S}$ ). They also found this TDT structure in temperature, but much less pronounced.

The 8-h $\mathrm{E}_{\mathrm{S}}$ characteristics at $110 \mathrm{~km}$ (Figure 5, right panel) are in good qualitative agreement with TDT in SABER temperature at the Southern Hemisphere, also supported by the CMAM results. Furthermore, both 8-h $E_{S}$ and TDT in SABER temperature observations reveal maxima during equinox at northern midlatitudes, while the pattern found at low northern latitudes (approximately $20^{\circ} \mathrm{N}$ ) do not match well. CMAM does not predict the spring maximum at midlatitudes. However, both the equinox maximum values and the asymmetry about the equator at $110 \mathrm{~km}$ during boreal summer agree with TIDI analyses by Yue et al. (2013).

\section{Conclusions}

The terdiurnal oscillations in the OFs of $\mathrm{E}_{\mathrm{S}}$ were analysed using observations derived from the FORMOSAT-3/ COSMIC satellite RO. The performed GPS RO technique does not allow tracking of a single $E_{S}$, but still holds sufficient information about the seasonal characteristics. Therefore, the 3-monthly mean zonal means from December 2006 to November 2012 were used for constructing a 6-year climatology. After the influence of the background ionisation was removed, we found two well-pronounced peaks of the 8-h $\mathrm{E}_{\mathrm{S}}$ amplitude during solstice above $100 \mathrm{~km}$, maximising between $10^{\circ}$ and $40^{\circ}$ in both hemispheres. A similar behaviour was observed for equinox conditions with the largest values occurring at low and midlatitudes in both hemispheres. An additional third maximum, which can be seen in modelled wind shear around the equator, is only weakly visible in $E_{S}$ due to the horizontal orientation of the magnetic field lines at Northern Hemisphere low latitudes. In general, the obtained global features above $100 \mathrm{~km}$ fit well with the TDT amplitude in zonal wind and the 8-h oscillation in vertical zonal wind shear simulated by MUAM. This is also supported by TDT satellite observations in temperature and zonal wind (Pancheva et al. 2013; 
Moudden and Forbes 2013; Yue et al. 2013) as well as the corresponding modelling results (Du and Ward 2010; Yue et al. 2013). We could also show that the influence of the TDT on $E_{S}$ formation is most likely restricted to heights above $100 \mathrm{~km}$, agreeing with the results reported by Moudden and Forbes (2013), who found a transition layer near $100 \mathrm{~km}$, where the dominating TDT amplitude switches from the region around the equator to middle and high latitudes. This might be the reason why nearly no similar features between TDT and 8-h $\mathrm{E}_{\mathrm{S}}$ are found between 85 and $100 \mathrm{~km}$.

This good qualitative agreement between $E_{S}$ observations and model wind shear was not expected because the model simulations of MUAM were highly simplified and the observations consider the TDT in temperature, which is not directly connected to the formation of $E_{S}$. Thus, the results indicate that the TDT also contributes to the formation of $E_{S}$ at heights $>100 \mathrm{~km}$, holding for latitudes $<60^{\circ} \mathrm{N} / \mathrm{S}$, while this is not the case for low northern latitudes.

\section{Competing interests}

The authors declare that they have no competing interests.

\section{Authors' contributions}

TF analysed 8-h oscillations in $E_{S}$ and wrote the final manuscript. CA extracted the $E_{S}$ signatures from the SNR of the GPS signal. PH performed circulation model simulations. CJ initiated the study and contributed to the interpretation. All authors read and approved the final manuscript.

\section{Acknowledgements}

T. Fytterer gratefully acknowledges funding by the Helmholtz Association of German Research Centres (HGF), grant VH-NG-624. We acknowledge UCAR (Boulder, USA) and NSPO (Taiwan) for the free provision of FORMOSAT-3/ COSMIC data and related support. We also acknowledge support by the Deutsche Forschungsgemeinschaft and Open Access Publishing Fund of Karlsruhe Institute of Technology.

\section{Author details}

${ }^{1}$ Institute for Meteorology and Climate Research, Karlsruhe Institute of Technology, Hermann-von-Helmholtz-Platz 1, Eggenstein-Leopoldshafen 76344, Germany. ${ }^{2}$ Department of Geodesy and Remote Sensing, German Research Centre for Geoscience GFZ, Telegrafenberg, Potsdam 14473, Germany. ${ }^{3}$ Potsdam Institute for Climate Impact Research, Telegrafenberg, Potsdam 14412, Germany. ${ }^{4}$ Institute for Meteorology, Universität Leipzig, Stephanstr, 3, Leipzig 04103, Germany.

Received: 30 March 2014 Accepted: 9 July 2014

Published: 28 July 2014

\section{References}

Arras C, Wickert J, Beyerle G, Heise S, Schmidt T, Jacobi C (2008) A global climatology of ionospheric irregularities derived from GPS radio occultation. Geophys Res Lett 35:L14809, doi:10.1029/2008GL034158

Arras C, Jacobi C, Wickert J (2009) Semidiurnal tidal signatures in sporadic E occurrence rates derived from GPS radio occultation measurements at higher midlatitudes. Ann Geophys 27:2555-2563, doi:10.5194/angeo-27-2555-2009

Beldon CL, Muller HG, Mitchell NJ (2006) The 8-hour tide in the mesosphere and lower thermosphere over the UK, 1988-2004. J Atmos Solar-Terr Phys 68:655-668, doi:10.1016/.j.jastp.2005.10.004

Bishop RL, Earle GD (2003) Metallic ion transport associated with midlatitude intermediate layer development. J Geophys Res 108:A11019, doi:10.1029/ 2002JA009411

CDAAC Team (2014) http://cdaac-www.cosmic.ucar.edu/cdaac/status.html, Accessed 13 Feb 2014
Du J, Ward WE (2010) Terdiurnal tide in the extended Canadian Middle Atmospheric Model (CMAM). J Geophys Res 115:D24106, doi:10.1029/2010JD014479

Fröhlich K, Pogoreltsev A, Jacobi C (2003) Numerical simulation of tides, Rossby and Kelvin waves with the COMMA-LIM model. Adv Space Res 32:863-868, doi:10.1016/S0273-1177(03)00416-2

Fytterer T, Arras C, Jacobi C (2013) Terdiurnal signatures in sporadic E layers at midlatitudes. Adv Radio Sci 11:1-7, doi:10.5194/ars-11-1-2013

Garcia-Fernandez M, Tsuda T (2006) A global distribution of sporadic E events revealed by means of CHAMP-GPS occultations. Earth Planets Space 58:33-36

Haldoupis C, Meek C, Christakis N, Pancheva D, Bourdillon A (2006) lonogram height-time-intensity observations of descending sporadic $E$ layers at midlatitude. J Atmos Solar-Terr Phys 68:539-557, doi:10.1016/j.jastp.2005.03.020

Haldoupis C, Pancheva D, Singer W, Meek C, MacDougall J (2007) An explanation for the seasonal dependence of midlatitude sporadic E layers. J Geophys Res 112:A06315, doi:10.1029/2007JA012322

Huang CM, Zhang SD, Yi F (2007) A numerical study on amplitude characteristics of the terdiurnal tide excited by nonlinear interaction between the diurnal and semidiurnal tides. Earth Planets Space 59:183-191

Jacobi C, Fytterer T (2012) The 8-h tide in the mesosphere and lower thermosphere over Collm (51.3 N; 13.0 E), 2004-2011. Adv Radio Sci 10:265-270, doi:10.5194/ars-10-265-2012

Marchuk GI (1967) Chislennye metody v prognoze pogody. Gidrometeorologicheskoye izdatylstva, Leningrad. English edition: Marchuk GI (1974) Numerical Methods in Weather Prediction. Academic, New York

Mathews JD (1998) Sporadic E: current views and recent progress. J Atmos Solar-Terr Phys 60:413-435, doi:10.1016/S1364-6826(97)00043-6

Matsuno T (1966) A finite difference scheme for time integrations of oscillatory equations with second order accuracy and sharp cutoff for high frequencies. J Meteorol Soc Jap 44:76-84

Moudden Y, Forbes JM (2013) A decade-long climatology of terdiurnal tides using TIMED/SABER observations. I Geophys Res Space Physics 118:4534-4550, doi:10.1002/jgra.50273

Pancheva D, Mukhtarov P, Smith AK (2013) Climatology of the migrating terdiurnal tide (TW3) in SABER/TIMED temperatures. J Geophys Res Space Physics 118:1755-1767, doi:10.1002/jgra.50207

Pogoreltsev Al, Vlasov AA, Fröhlich K, Jacobi C (2007) Planetary waves in coupling the lower and upper atmosphere. J Atmos Solar-Terr Phys 69:2083-2101, doi:10.1016/j.jastp.2007.05.014

Richards PG, Fennelly JA, Torr DG (1994) EUVAC: A solar EUV flux model for aeronomic calculations. J Geophys Res Space Physics 99:8981-8992, doi:10.1029/94JA00518. (Correction. J Geophys Res 99(13283):1994, doi:10.1029/94JA01446)

Roble RG (1995) Energetics of the mesosphere and thermosphere. In: Johnson RM, Killeen TL (eds) The upper mesosphere and lower thermosphere: a review of experiment and theory, vol 87. Geophys Monogr, Washinton D.C., pp 1-21

Smith AK (2000) Structure of the terdiurnal tide at $95 \mathrm{~km}$. Geophys Res Lett 27:177-180. doi:10.1029/1999GL010843.

Smith AK, Ortland DA (2001) Modeling and analysis of the structure and generation of the terdiurnal tide. J Atmos Sci 58:3116-3134, doi:10.1175/ 1520-0469(2001)058 < 3116:MAAOTS > 2.0.CO;2

Strang G (1968) On the construction and comparison of difference schemes. SIAM J Numer Anal 5:516-517, doi:10.1137/0705041

Teitelbaum H, Vial F, Manson AH, Giraldez R, Massebeuf M (1989) Non-linear interactions between the diurnal and semidiurnal tides: terdiurnal and diurnal secondary waves. J Atmos Solar-Terr Phys 51:627-634, doi:10.1016/0021-9169 (89)90061-5

Whitehead J (1961) The formation of the sporadic E layer in the temperate zones. J Atmos Terr Phys 20:49-58, doi:10.1016/0021-9169(61)90097-6

Wu DL, Ao O, Hajj GA, de la Torre JM, Mannucci AJ (2005) Sporadic E morphology from GPS-CHAMP radio occultation. J Geophys Res 110, A01306, doi:10.1029/2004JA010701

Yue J, Xu J, Chang LC, Wu Q, Liu H-L, Lu X, Russell J III (2013) Global structure and seasonal variability of the migrating terdiurnal tide in the mesosphere and lower thermosphere. J Atmos Solar-Terr Phys 105-106:191-198, do::10.1016/j.jastp.2013.10.010

Zuo X, Wan W (2008) Planetary wave oscillations in sporadic E layer occurrence at Wuhan. Earth Planets Space 60:647-652

\section{doi:10.1186/1880-5981-66-79}

Cite this article as: Fytterer et al:: Global distribution of the migrating terdiurnal tide seen in sporadic $\mathrm{E}$ occurrence frequencies obtained from GPS radio occultations. Earth, Planets and Space 2014 66:79. 